\title{
Movement patterns of American eels (Anguilla rostrata) between salt- and freshwater in a coastal watershed, based on otolith microchemistry
}

Heather M. Lamson • Jen-Chieh Shiao •

Yoshiyuki Iizuka • Wann-Nian Tzeng • David K. Cairns

Published online: 26 June 2006

(C) Springer-Verlag 2006

\section{Mar Biol (2006) DOI 10.1007/s00227-006-0308-2}

Unfortunately Table 3 contained errors. The correct Table 3 is shown below.

The online version of the original article can be found at http://dx.doi.org/10.1007/s00227-006-0308-2.

H. M. Lamson

Biology Department, University of New Brunswick,

Fredericton, NB, Canada E3B 6E1

J.-C. Shiao

Institute of Zoology, Academia Sinica, Nankang,

Taipei 11529, Taiwan, ROC

Y. Iizuka

Institute of Earth Sciences, Academia Sinica,

Nankang, Taipei 11529, Taiwan, ROC

W.-N. Tzeng

Institute of Fisheries Sciences, National Taiwan University,

Taipei 10617, Taiwan, ROC

D. K. Cairns ( $\square)$

Department of Fisheries and Oceans, Box 1236,

Charlottetown, PE, Canada C1A 7M8

e-mail: cairnsd@dfo-mpo.gc.ca 


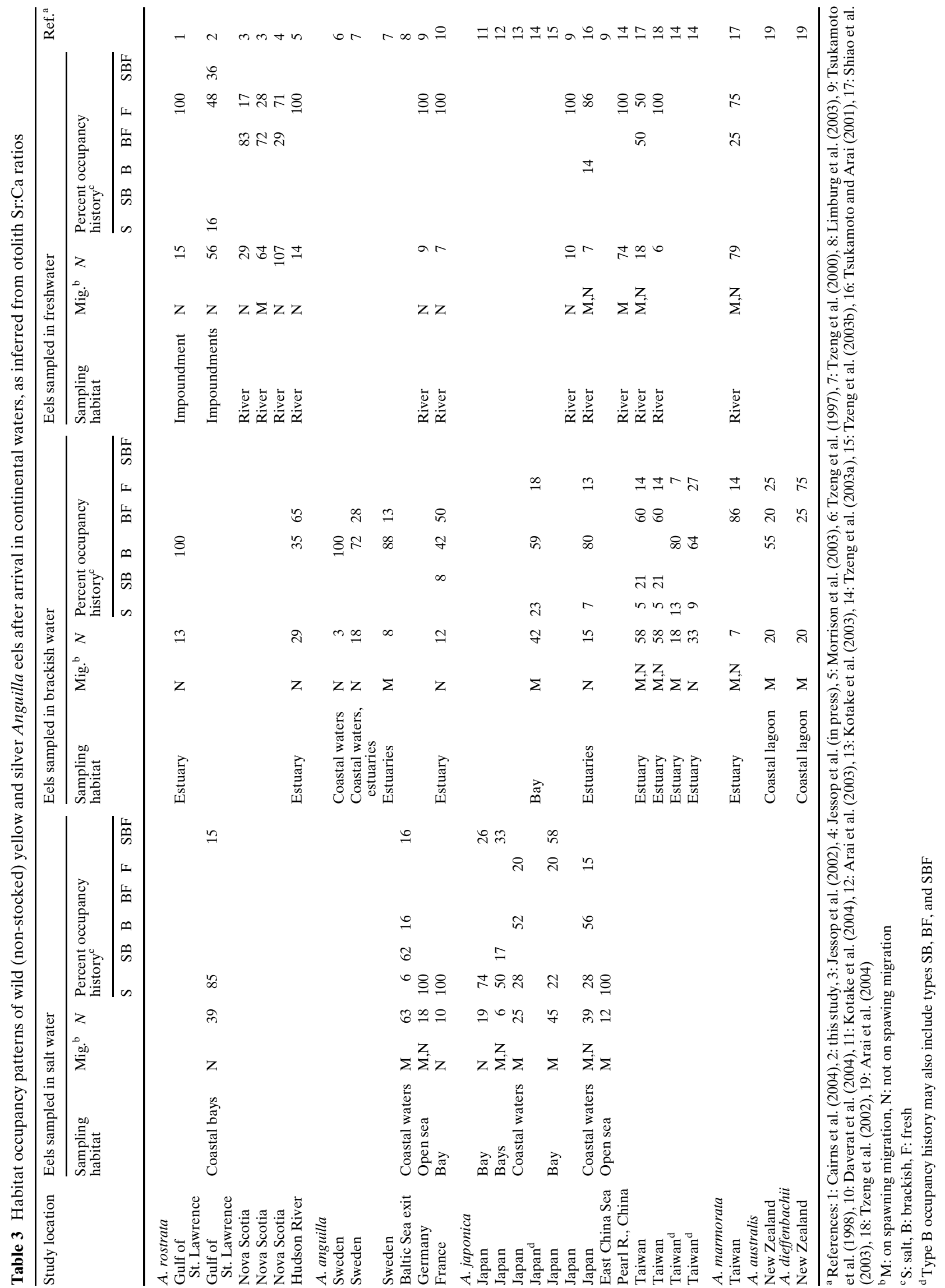

